Research

Open Access

\title{
Increased cardiac index due to terbutaline treatment aggravates capillary-alveolar macromolecular leakage in oleic acid lung injury in dogs
}

\author{
Raphael Briot, Sam Bayat, Daniel Anglade, Jean-Louis Martiel and Francis Grimbert
}

\begin{abstract}
Laboratoire TIMC, Equipe PRETA, Unité Mixte de Recherche 5525 du Centre National de Recherche Scientifique, Université Joseph Fourier, Centre Hospitalier Universitaire, Grenoble, 38043 cedex 09, France

Corresponding author: Raphael Briot, rbriot@chu-grenoble.fr
\end{abstract}

Received: 2 Sep 2009 Revisions requested: 23 Sep 2009 Revisions received: 30 Sep 2009 Accepted: 21 Oct 2009 Published: 21 Oct 2009

Critical Care 2009, 13:R166 (doi:10.1186/cc8137)

This article is online at: http://ccforum.com/content/13/5/R166

(C) 2009 Briot et al.; licensee BioMed Central Ltd.

This is an open access article distributed under the terms of the Creative Commons Attribution License (http://creativecommons.org/licenses/by/2.0), which permits unrestricted use, distribution, and reproduction in any medium, provided the original work is properly cited.

\begin{abstract}
Introduction We assessed the in vivo effects of terbutaline, a beta2-agonist assumed to reduce microvascular permeability in acute lung injury.

Methods We used a recently developed broncho-alveolar lavage (BAL) technique to repeatedly measure (every $15 \mathrm{~min}$. for 4 hours) the time-course of capillary-alveolar leakage of a macromolecule (fluorescein-labeled dextran) in 19 oleic acid (OA) lung injured dogs. BAL was performed in a closed lung sampling site, using a bronchoscope fitted with an inflatable cuff. Fluorescein-labeled Dextran (FITC-D70) was continuously infused and its concentration measured in plasma and BAL fluid. A two-compartment model (blood and alveoli) was used to calculate $\mathrm{KAB}$, the transport rate coefficient of FITC-D70 from blood to alveoli. KAB was estimated every 15 minutes over 4 hours. Terbutaline intra-venous perfusion was started $90 \mathrm{~min}$.
\end{abstract}

after the onset of the injury and then continuously infused until the end of the experiment.

Results In the non-treated injured group, the capillary-alveolar leakage of FITC-D70 reached a peak within 30 minutes after the OA injury. Thereafter the FITC-D70 leakage decreased gradually until the end of the experiment. Terbutaline infusion, started 90 min after injury, interrupted the recovery with an aggravation in FITC-D70 leakage.

Conclusions As cardiac index increased with terbutaline infusion, we speculate that terbutaline recruits leaky capillaries and increases FITC-D70 leakage after OA injury. These findings suggest that therapies inducing an increase in cardiac output and a decrease in pulmonary vascular resistances have the potential to heighten the early increase in protein transport from plasma to alveoli within the acutely injured lung.

\section{Introduction}

Acute lung injury (ALI) is a major syndrome in patients in the intensive care unit, and it has a high mortality rate. An increased capillary-alveolar permeability to plasma proteins is an early marker of the acute phase of lung injury andcontributes to the development of fibroproliferation [1] and lung fibrosis, which both contribute to a negative outcome [2]. Plasma proteins that flood the alveoli include pro-coagulant factors and initiate a local coagulation cascade [3]. A relation between the early alteration of capillary-alveolar permeability to proteins and the fibrotic process has been confirmed in clinical studies [4]. The finding that in acute respiratory distress syndrome (ARDS) patients, bronchoalveolar lavage (BAL) protein levels decreased over time only in survivors suggests the involvement of the amplification of inflammatory responses due to alveolar protein flooding [5]. If a high BAL protein concentration in patients with ARDS predicts a higher risk of late fibrosis, any therapy aimed at reducing plasma protein accumulation in the interstitium and alveoli is of potential benefit.

ABP: systemic arterial blood pressure; ALI: acute lung injury; ALTA: AlbuteroL for the Treatment of ALI; ANOVA: analysis of variance; ARDS: acute respiratory distress syndrome; BAL: broncho-alveolar lavage; BALTI: Beta-Agonist Lung Injury Trial; CO: cardiac output; FiO2: fraction of inspired oxygen; FITC-D70: fluorescein-labeled dextran; Hcl: Hydrochloric acid; $K_{A B}$ : coefficient of capillary-alveolar leakage; OA: oleic acid; PaO2: partial pressure of oxygen in arterial blood; PAOP: pulmonary arterial occlusion pressure; PAP: pulmonary arterial blood pressure; Pcap: pulmonary capillary pressure; PET: Positron emission tomography; PVR: total pulmonary vascular resistances; SEM: standard error of the mean; SpO2: pulsed oxygen saturation; Vtn: volume of the lavaged lung segment. 
We recently developed a modified $B A L$ technique to monitor the capillary-alveolar leakage of macromolecules over several hours [6]. This technique allows the assessment of therapies aimed at slowing plasma protein accumulation in alveoli.

Several studies suggest a potential role for $\beta 2$-agonists in the treatment of ARDS. These agents have been shown to reduce pulmonary neutrophil sequestration and activation, enhance surfactant secretion and modulate the inflammatory and coagulation cascades [7,8]. $\beta 2$-adrenergic agonists have shown ability to reduce lung endothelial injury [9] and they are well known for their ability to enhance the epithelial fluid reabsorption by stimulating the activity and the expression of the epithelial sodium channels [10]. However, the results of clinical studies on $\beta 2$-agonists effects in ARDS are controversial. The Beta-Agonist Lung Injury Trial (BALTI) [11]showed that intravenous albuterol treatment reduces extravascular lung water in patients with ARDS; but the recent study "AlbuteroL for the Treatment of ALI" (ALTA) [12] failed to find a beneficial effect of aerosolized albuterol therapy in a large randomized, placebo-controlled trial. Also, several in vivo studies showed no beneficial effects of $\beta 2$-agonist therapy, in terms of protein accumulation in injured lungs $[13,14]$. Hemodynamic effects of $\beta 2$-agonists may interfere with other potentially beneficial effects and may explain some of these contradictory results in patients with lung injury [15].

The goal of the present study was therefore to evaluate the effects of terbutaline, a widely used $\beta 2$-agonist, on the early increase in macromolecular permeability of the capillary-alveolar barrier following lung injury. We used a well-known in vivo dog model of oleic acid (OA) lung injury in which we assessed the overall effect of terbutaline, both on protein leakage through the capillary-alveolar barrier and on pulmonary hemodynamics.

\section{Materials and methods Animal preparation}

The experiments were performed on 19 anesthetized dogs. The experiments were carried out in accordance with the applicable French and European Community regulations. Animals were intubated and mechanically ventilated using $2 \%$ halothane to maintain anesthesia. Tidal volume was $10 \mathrm{~mL} / \mathrm{kg}$ and respiratory frequency was adjusted between 12 and 20 breathes/minute to keep end-tidal $\mathrm{CO}_{2}$ within normal range. Fraction of inspired oxygen $\left(\mathrm{FiO}_{2}\right)$ was adjusted to keep hemoglobin oxygen saturation above $95 \%$, as measured by pulse oxymetry $\left(\mathrm{SpO}_{2}\right)$. Arterial blood gases were measured every hour following a 10-minute period of ventilation with an $\mathrm{FiO}_{2}$ of $100 \%$.

In injury experiments, animals were equipped with a pulmonary artery catheter and a catheter in the femoral artery. The following parameters were recorded: systemic arterial blood pressure (ABP), pulmonary arterial blood pressure (PAP), pulmonary arterial occlusion pressure (PAOP), and cardiac output (CO). Pulmonary capillary pressure (Pcap) was estimated from the back-extrapolation of the transitory pressure drop (between 0.2 and 2 seconds) following the inflation of the balloon of the pulmonary arterial catheter, using a doubleexponential fit [16]. As control animals were destined for other later experiments, they were not equipped with invasive catheters.

\section{Broncho-alveolar lavage procedure}

This modified BAL technique has been extensively described in a previous publication [6]. Briefly, in order to perform repeated $B A L$ in a closed lung segment, an inflatable balloon was adapted to the extremity of a bronchoscope. Six initial BAL cycles were performed sequentially, in order to obtain a rapid saturation of the lavaged lung segment. Thereafter, one BAL cycle was performed every 15 minutes for the next three hours.

\section{Sample processing}

Prior to the procedure, a batch solution of $500 \mathrm{~mL}$ of fresh lavage fluid was prepared by adding ${ }^{125}$-albumin (Cis Bio International, Paris, France) to saline ( $\mathrm{NaCl}: 0.9 \mathrm{~g} \%$ ) at a final activity of $5 \mu \mathrm{Ci} / \mathrm{L}$ as a dilution indicator of the lavage fluid inside the lung.

Thirty minutes before BAL, a $6 \mathrm{mg} / \mathrm{kg}$ bolus of a fluorescein isothiocyanate-labeled dextran (FITC-D70; average molecular mass, 73,100 daltons; Sigma, St. Quentin Fallavier, France) was injected, followed by an infusion of $6 \mathrm{mg} / \mathrm{kg} / \mathrm{hour}$ in order to obtain a steady FITC-D70 concentration in plasma. Indicator concentrations were measured after the experiment. ${ }^{125} \mathrm{~J}$ albumin activity was measured in BAL. FITC-D70 concentrations were measured in plasma and BAL fluid by fluorescence spectrophotometry, using excitation and emission wavelengths of 482 and $521 \mathrm{~nm}$, respectively. The data analysis was performed using a two-compartment model where the FITC-D70 transport rate coefficient $K_{A B}\left(\mathrm{~min}^{-1}\right)$ from blood to alveoli was estimated (see details of calculations in Additional data file 1).

\section{Experimental protocol}

The study was performed in four separate groups.

In group $1(n=3)$ control animals were not injured with $O A$ and received no terbutaline. In group $2(n=3)$ animals were not injured but received a terbutaline treatment.

In groups 3 and 4 the ALI was induced 30 minutes after the initial saturation BAL procedure. Every two minutes, $0.3 \mathrm{ml}$ boluses of $\mathrm{OA}$ were injected into the superior vena cava through the proximal lumen of the pulmonary artery catheter up to a total dose of $0.08 \mathrm{ml} / \mathrm{kg}$. Group $3(\mathrm{n}=7)$ received OA injury without any treatment. In group $4(n=6)$ the terbutaline treatment was administered using an infusion of $0.25 \mathrm{mg} / \mathrm{kg} /$ 
min started 90 minutes after OA injury. Thereafter the terbutaline was continuously infused until the end of the experiment.

\section{Statistics}

A statistical analysis was performed through Statview software (SAS Institute Inc. Cary, NC, USA). Group data are summarized as the mean \pm standard error of the mean (SEM). First we compared global data by analysis of variance (ANOVA). Thereafter intra-group data were compared using a post-hoc test of Tukey-Kramer. Mann-Whitney rank-sum tests were used for two-group comparisons. We used linear regression models to determine individual correlations between $K_{A B}$ and hemodynamic data. Differences with a $P<0.05$ were considered as significant.

\section{Results}

The volume of the lavaged lung segment $(V t n)$ remained stable $(63.1 \pm 3.1 \mathrm{~mL})$ throughout the sequential lavage cycles. The FITC-D70 plasma concentration was also stable throughout the experiment $(0.15 \pm 0.01 \mathrm{mg} / \mathrm{mL})$.

The alveolar concentration of FITC-D70 remained near zero in all groups before the onset of the injury. In injured animals (groups 3 and 4), the alveolar FITC-D70 concentration rose immediately after the OA infusion. In group 3 (OA) the FITCD70 concentration reached a plateau during the last hour of the experiment, whereas in group 4 (OA + terbutaline) the start of terbutaline perfusion was followed by a second rise in BAL FITC-D70 concentration (Figure 1).

\section{Figure 1}

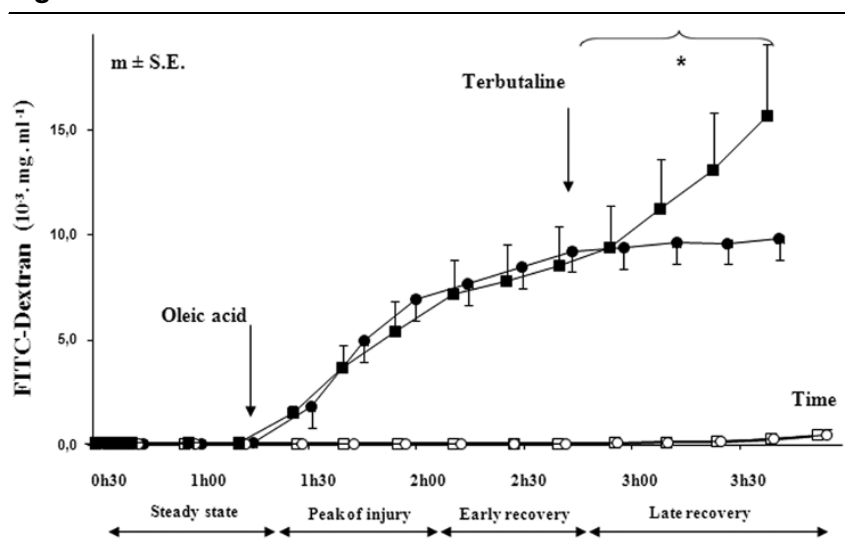

FITC-D70 concentration in broncho-alveolar lavage. Open circles $=$ group 1 which was a control group $(n=3)$; Open squares = group 2 which was a control group with terbutaline infusion $(n=3)$; Filled circles $=$ group 3 which was the OA injury group $(n=7)$; Filled squares $=$ group 4 which was the $O A$ injury with late terbutaline infusion group (n $=6)$. ${ }^{\star} P<0.05$ early recovery versus late recovery in group 4 (OA + terbutaline) (intra-group comparison by analysis of variance and the post-hoc test of Tukey-Kramer). FITC-D70 = fluorescein-labeled dextran; $\mathrm{OA}=$ oleic acid.

\section{Coefficient of capillary-alveolar leakage $\left(K_{A B}\right)$}

The FITC-D70 capillary-alveolar transport rate coefficient from blood to alveoli $\left(K_{A B}\right)$ was near zero in groups 3 and 4 before OA injury, a period defined as steady state.

Although $K_{A B}$ remained near zero in control groups 1 and 2 throughout the experiment, this coefficient rose markedly in OA-injured animals (groups 3 and 4) immediately after the onset of injury. $K_{A B}$ reached a peak value (peak of injury) 30 minutes after the $O A$ infusion and decreased gradually thereafter. Within this recovery period, we distinguished two phases: early recovery (first $\mathbf{4 5}$ minutes after the peak of injury) and late recovery (last hour of the experiment).

In group 3 (OA injury) $K_{A B}$ recovered slowly, while in group 4 $\left(\mathrm{OA}+\right.$ terbutaline) $K_{A B}$ rose again after the onset of terbutaline administration (Figure 2).

\section{Hemodynamics values}

In group 4 (OA + terbutaline) the cardiac index and the PAP increased and remained elevated following terbutaline administration. Such an increase was not observed in group 3 (OA). Total pulmonary vascular resistances (PVR) increased after $\mathrm{OA}$ injury and remained elevated in non-treated animals (group 3). Terbutaline infusion reduced the elevated PVR approximately to the pre-injury level. The hematocrit was constant throughout the experiment (mean value, $0.36 \pm 0.1$ ) with no significant difference between the different groups. The partial pressure of arterial oxygen $\left(\mathrm{PaO}_{2}\right) / \mathrm{FiO}_{2}$ ratio decreased markedly at the onset of the injury and did not recover later. There

\section{Figure 2}

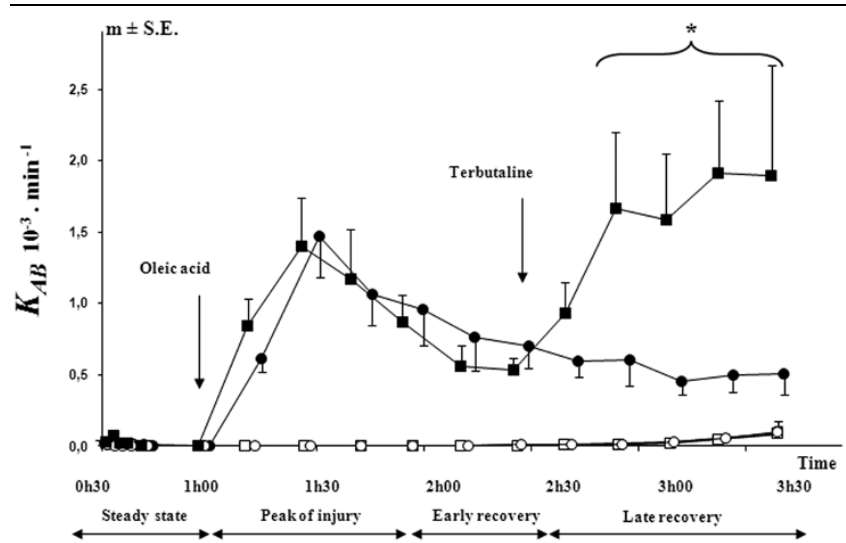

Time course of $K_{A B}$, the transport rate constant for FITC-D70 from blood to alveoli. Open circles = group 1 which was a control group ( $\mathrm{n}$ $=3$ ); Open squares = group 2 which was a control group with terbutaline infusion $(n=3)$; Filled circles $=$ group 3 which was the OA injury group $(n=7)$; Filled squares = group 4 which was the OA injury with late terbutaline infusion group $(\mathrm{n}=6) .{ }_{\star} P<0.05$ early recovery versus late recovery in group 4 (OA + terbutaline) (intra-group comparison by analysis of variance and the post-hoc test of Tukey-Kramer). FITC-D70 $=$ fluorescein-labeled dextran; $K_{A B}=$ coefficient of capillary-alveolar leakage; $\mathrm{OA}=$ oleic acid. 
was no significant difference between groups at any stages of the experiment.

Hemodynamic and gas exchange data of groups 3 and 4 are summarized in Table 1.

\section{Discussion}

The main finding of this study is that the capillary-alveolar transport of FITC-D70 is increased by terbutaline infusion starting 90 minutes after the onset of an OA-induced lung injury. The participation of a terbutaline-induced increase in $\mathrm{CO}$ and PAP is suspected in the aggravation of lung injury.

\section{Methodological considerations}

Our technique of capillary-alveolar permeability measurement modified a BAL technique previously described [17] and now allow the permeability to be monitored over extended periods of time. This new method has been fully described in a prior publication [6] and will be only briefly discussed here. This technique allows sampling of a lung segment saturated with BAL fluid every 15 minutes. Our BAL sampling technique offers a higher frequency of measurements and a greater sensitivity compared with the other techniques of lung permeability measurement either by lung lymph collection or the external radio-detection. This method differs also from the measurement of alveolar fluid clearance, which reflects the alveolar epithelium function, but variations are not necessarily correlated with the permeability to proteins of the capillary-alveolar barrier [18]. $K_{A B}$, our transport rate coefficientof FITC-D70 from blood to alveoli, reflects the sum of capillary endothelial, interstitial and alveolar epithelial permeabilities arranged as resistances in series. It reflects also the perfusion surface area of lung capillaries. In normal conditions, thistransport rate coefficientis near zero. In this study, the time course and the values

Table 1

\begin{tabular}{|c|c|c|c|c|}
\hline Mean \pm SEM & $\begin{array}{l}\text { Steady state } \\
30-75 \text { min }\end{array}$ & $\begin{array}{l}\text { Peak } \\
75-120 \mathrm{~min}\end{array}$ & $\begin{array}{l}\text { Early recovery } \\
120-180 \text { min }\end{array}$ & $\begin{array}{l}\text { Late recovery } \\
180-240 \mathrm{~min}\end{array}$ \\
\hline \multicolumn{5}{|l|}{$\mathrm{ABP}(\mathrm{mmHg})$} \\
\hline Group 3 & $95.4 \pm 4.3$ & $75.3 \pm 9.0$ & $84.7 \pm 7.8$ & $102.8 \pm 3.3$ \\
\hline Group 4 & $93.0 \pm 8.1$ & $82.5 \pm 4.6$ & $93.8 \pm 8.3$ & $91.3 \pm 3.1$ \\
\hline \multicolumn{5}{|c|}{ Cardiac index $(\mathrm{L} / \mathrm{min} / \mathrm{kg})$} \\
\hline Group 3 & $0.16 \pm 0.01$ & $0.09 \pm 0.01$ & $0.10 \pm 0.01$ & $0.12 \pm 0.01$ \\
\hline Group 4 & $0.14 \pm 0.01$ & $0.13 \pm 0.01$ & $0.13 \pm 0.09$ & $0.24 \pm 0.02$ * \\
\hline \multicolumn{5}{|l|}{ PAP $(\mathrm{mmHg})$} \\
\hline Group 3 & $17.1 \pm 1.2$ & $13.2 \pm 1.3$ & $15.2 \pm 1.3$ & $18.5 \pm 1.8$ \\
\hline Group 4 & $17.9 \pm 1.9$ & $18.4 \pm 1.4$ & $18.2 \pm 1.5$ & $24.2 \pm 0.9$ * \\
\hline \multicolumn{5}{|l|}{ Pcap $(\mathrm{mmHg})$} \\
\hline Group 3 & $10.5 \pm 1.5$ & $10.5 \pm 1.5$ & $9.7 \pm 1.1$ & $10.3 \pm 0.5$ \\
\hline Group 4 & $12.6 \pm 1.6$ & $14.0 \pm 1.1$ & $13.2 \pm 1.3$ & $15.6 \pm 1.2$ \\
\hline \multicolumn{5}{|l|}{ PAOP $(\mathrm{mmHg})$} \\
\hline Group 3 & $6.9 \pm 0.6$ & $6.3 \pm 0.9$ & $6.0 \pm 1.0$ & $6.0 \pm 0.4$ \\
\hline Group 4 & $9.4 \pm 1.5$ & $9.3 \pm 1.0$ & $9.0 \pm 1.7$ & $10.0 \pm 0.7$ \\
\hline \multicolumn{5}{|c|}{ PVR $(\mathrm{mmHg} / \mathrm{L} / \mathrm{min} / \mathrm{kg})$} \\
\hline Group 3 & $63.7 \pm 7.6$ & $76.8 \pm 5.5$ & $92.0 \pm 10.2$ & $104.1 \pm 12.6$ \\
\hline Group 4 & $60.7 \pm 11.5$ & $70.1 \pm 15.1$ & $71.3 \pm 12.1$ & $58.9 \pm 11.5$ * \\
\hline \multicolumn{5}{|c|}{$\mathrm{PaO} 2 / \mathrm{FiO} 2$ (kPa) } \\
\hline Group 3 & $36.2 \pm 0.7$ & $14.5 \pm 4.4$ & $10.5 \pm 2.9$ & $10.8 \pm 3.7$ \\
\hline Group 4 & $27.9 \pm 2.0$ & $16.6 \pm 2.7$ & $15.3 \pm 3.2$ & $15.2 \pm 3.1$ \\
\hline
\end{tabular}

$\mathrm{ABP}=$ systemic arterial blood pressure; $\mathrm{FiO} 2=$ fraction of inspired oxygen; $\mathrm{PaO} 2=$ partial pressure of oxygen in arterial blood; $\mathrm{PAOP}=$ pulmonary arterial occlusion pressure; PAP = pulmonary arterial blood pressure; Pcap = pulmonary capillary pressure; PVR = total pulmonary vascular resistances; SEM = standard error of the mean.

Group $3=\mathrm{OA}$ injury without terbutaline $(n=7)$; Group $4=\mathrm{OA}+$ terbutaline $(n=6) ;{ }^{*} P<0.05$ early recovery versus late recovery in group 4 (OA + terbutaline) (intra-group comparison by analysis of variance and the post-hoc test of Tukey-Kramer). 
of $K_{A B}$ after $\mathrm{OA}$ injury were consistent with our prior findings [6] with a peak of injury followed by a slow recovery period. In this new series we studied specifically the effects of a terbutaline infusion started 90 minutes after OA injury. The terbutaline administration aggravated the capillary-alveolar transport of FITC-D70.

\section{Possible explanations for the observed terbutaline effects}

The capillary-interstitial macromolecular flow through the endothelial barrier is essentially convective (i.e., drawn by capillary fluid filtration) when the endothelium is injured [19]. This elevation in convective transport can result from a decrease in the reflection coefficient for proteins of the capillary-alveolar barrier, or from an increase in capillary fluid filtration.

It is unlikely that the terbutaline diminished the reflection coefficient for proteins of the membrane. Indeed $\beta$-agonists are known for their anti-inflammatory effects and for improving the tightness of the endothelial cells $[7,8]$.

Although $\beta 2$-adrenergic agonists, such as terbutaline, stimulate water clearance by epithelial cells [10], we rule out a significant participation of fluid reabsorption in the post terbutaline rebound of FITC-D70 transport. Our BAL sampling process is designed to ensure a high alveolar fluid renewal (48\%/h; see calculations in the Additional data file 1), largely higher than the potential alveolar epithelial fluid reabsorption, even when enhanced by terbutaline. On the other hand, terbutaline may have increased the fluid filtration through an elevation of the capillary pressure or an augmentation of the perfusion surface area. Indeed, our data have shown significant correlations in group $4(\mathrm{OA}+$ terbutaline) between the coefficient of FITC-D70 leakage $K_{A B}$ and Pcap, cardiac index and PAP (Figure 3).

We observed a non-significant trend towards an increased Pcap after terbutaline administration as compared with the early recovery period. In normal lung, an increase in Pcap leads to a large elevation in transvascular fluid filtration but a minor elevation in transvascular protein filtration [20]. In contrast, in lung injury entailing altered capillary-alveolar permeability, any increase in Pcap induces a large elevation in both transvascular fluid and protein filtration [21].

Terbutaline may also have increased the perfusion surface area and recruited leaky injured capillaries, which were initially derecruited by the hypoxic vasoconstriction. Several arguments plead in favor of this hypothesis. After terbutaline administration we observed a marked increase in cardiac index which is a well-known effect of the $\beta$-agonists. In normal lung, an increase in $\mathrm{CO}$ does not induce, by itself, an increase in transvascular fluid and protein filtration [22]. In contrast, in an OA-injured lung, increasing CO may worsen lung water accumulation likely by pulmonary vascular recruitment [23]. We
Figure 3
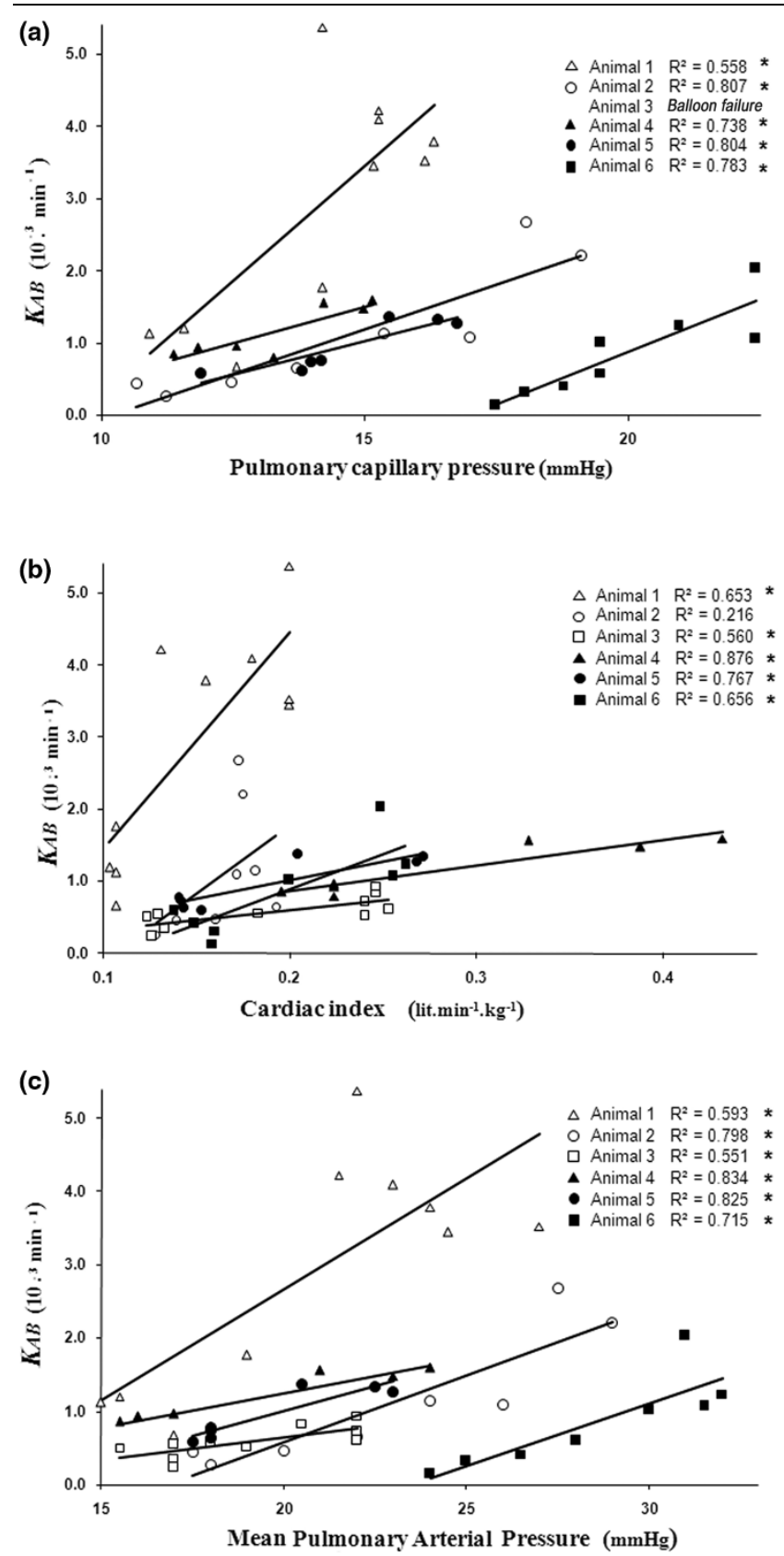

Correlations of $K_{A B}$ in group $4(\mathrm{OA}+$ terbutaline). Individual correlations in group 4 (OA + terbutaline) (a) between the FITC-D70 leakage index $K_{A B}$ and capillary pressure; (b) between $K_{A B}$ and cardiac index; and (c) between $K_{A B}$ and mean Pulmonary Arterial Pressure (by linear regression). FITC-D70 = fluorescein-labeled dextran; $K_{A B}=$ coefficient of capillary-alveolar leakage; $\mathrm{OA}=$ oleic acid.

also observed a significant reduction in PVR after terbutaline administration. Indeed, while OA injury initially elevated PVR, terbutaline administration reduced these elevated resistances to pre-injury levels. This drop in PVR, together with the increase in cardiac index, is consistent with an increase in perfusion surface area related to terbutaline infusion. b2-agonists 
are pulmonary vasodilators and terbutaline may also have lifted the hypoxic vasoconstriction and increased blood flow in injured lung zones, resulting in increased protein transport.

Therefore, we speculate that the rebound in FITC-D70 leakage, observed in our series during terbutaline perfusion, was provoked by an increase in perfusion surface area, associated to a small elevation of the Pcap.

\section{Recruitment of 'blind capillaries'}

$\mathrm{OA}$ injury induces a hypoxic and mediator-induced active vasoconstriction, a perivascular compression by edema, and an intravascular obstruction by thromboembolism or endothelial swelling $[24,25]$. The active vasoconstriction is a pre-capillary and protective phenomenon. It accounts for approximately $50 \%$ of the pulmonary hypertension and is partially reversible. Eliminating this adaptive vasoconstriction response may dramatically deteriorate OA-injured lungs $[26,27]$. Several studies in intact dogs $[28,29]$ have shown an increase in pulmonary venous resistance following OA injury. In the present study we also observed a trend, although not significant, towards an increase in pulmonary venous resistance during the peak of OA injury. This enhancement in postcapillary pulmonary venous resistance after $\mathrm{OA}$ injury may be mediated by thromboxane $A 2$ release [30], sympathetic vasoconstriction [29], or microvascular obstruction [31]. Anglade and colleagues [32] have shown in OA-injured rabbit lung preparations that the increase in filtration surface area and capillary recruitment is larger when entailed by an elevation in $\mathrm{CO}$ than by an elevation in pulmonary venous pressure. These authors hypothesized that an elevation in $\mathrm{CO}$ could result in the re-opening of non-flowing leaky capillaries in zone 1 , called 'blind capillaries' (i.e. opened at their arterial end and obstructed at their venous end) with a filtration pressure at the level of arteriolar pressure (Figure 4). This hypothesis is consistent with the observations of positron emission tomography (PET) imaging in OA injury, showing a greater reduction in blood flow in the most injured areas [33]. The injured capillaries are highly permeable vessels and their recruitment may considerably increase fluid and protein leak upstream of the obstruction.

In the present study, we speculate that the rebound of capillary-alveolar leakage, observed after terbutaline infusion, is consistent with the hypothesis of an arterial re-opening of blind injured capillaries in zone 1. Also, the elevation in $\mathrm{CO}$ and in PAP may have shifted downstream the obstruction point under zone 2 conditions towards the venous ends of capillaries and venules (Figure 4).

\section{Limitations of the study}

Our preparation was designed only to study the early phase of the lung injury. BAL is known to cause a depletion in alveolar surfactant [34] and increase the recruitment of neutrophils $[35,36]$, but it does not cause a significant change in the pro-

\section{Figure 4}
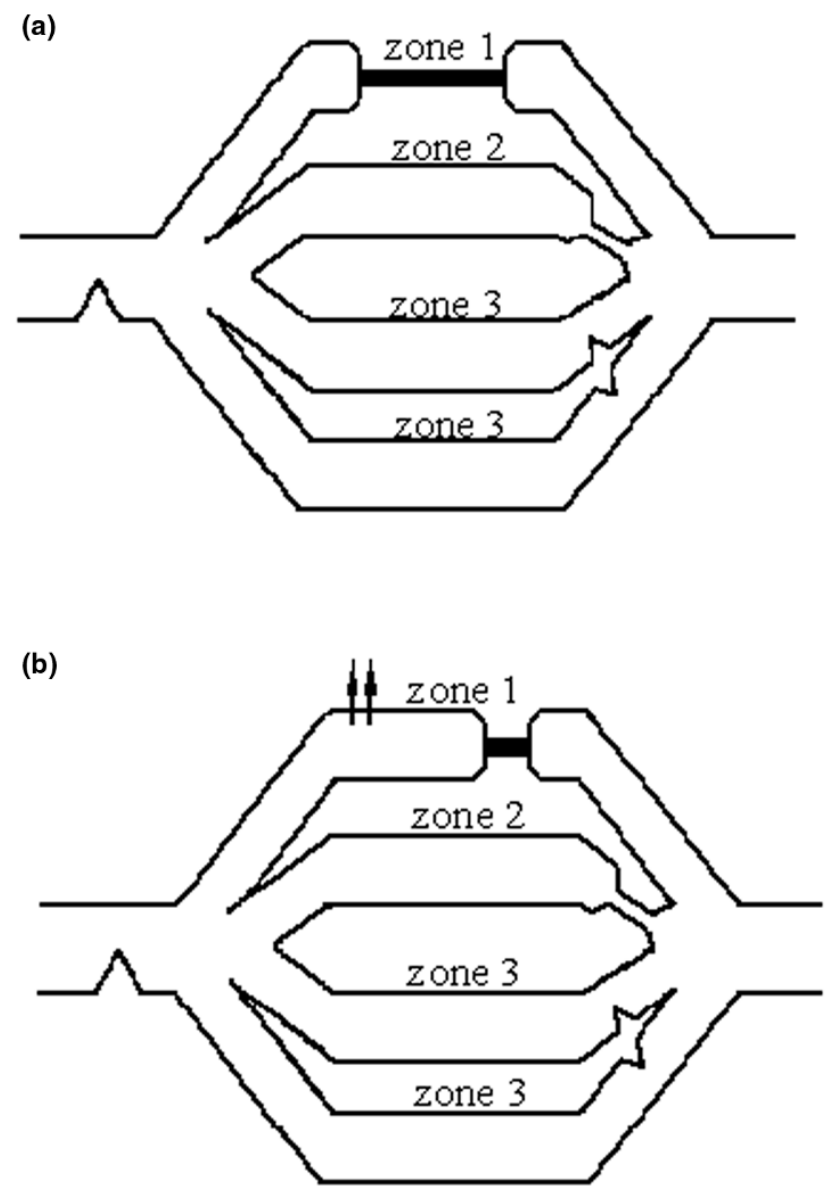

Recruitment of blind capillaries. Adapted from Anglade and colleagues [32] with permission. Model of circulation includes four branches of pulmonary circulation lying in parallel in same horizontal plane. Flow-limiting compression point in zone 2 lung is indicated by narrowing of vascular branch. (a) OA-injured lung before the terbutaline-increase in cardiac index and PAP. (b) Filling of blind vessels in zone 1, (i.e., opened at their arterial end and obstructed at their venous end). Corresponding injured capillaries may filter considerably (arrows) because filtration pressure in these non-flowing capillaries is at the level of pulmonary arteriolar pressure. In addition steep pressure gradient observed during increased cardiac index may also move downstream the obstruction point in zone 2 lung and increase filtration surface area. $\mathrm{OA}=$ oleic acid; $\mathrm{PAP}=$ pulmonary arterial blood pressure.

tein permeability of the epithelial barrier during the first four hours [37]. In the same manner, in our data, we observed a spontaneous aggravation of lung permeability, in control animals, when the experiments were prolonged beyond four hours [6]. Therefore, the BAL technique cannot be extended over a long period. Due to this time limitation, we cannot exclude that the rebound of FITC-D70 leakage, observed with terbutaline infusion, might be only a transient side effect of terbutaline, lately counterbalanced by $\beta$-agonist beneficial effects. Other studies have shown that $\beta 2$-agonist action on capillary-alveolar membrane may be delayed for several hours. 
McAuley and colleagues [9] have observed a positive effect of salmeterol four hours, but not two hours, after the onset of an hydrochloric acid $(\mathrm{Hcl})$ lung injury in rats. In the two recent large clinical studies on $\beta 2$-agonist treatment in ARDS (BALTI [11] and ALTA [12]), patients were recruited approximately 24 hours after the beginning of lung injury and in the BALTI study, intravenous infusion of salbutamol reduces extravascular lung water in patients after a 72-hour delay.

Such delayed action might explain the lack of efficacy of terbutaline on capillary-alveolar permeability in our series. Other studies should be specially designed to evaluate the terbutaline effects beyond the first four hours following OA injury.

The OA injury model is also, by itself, a limitation of our study. $\mathrm{OA}$ is known to provoke a severe injury that probably overwhelmed the beneficial effects of $\beta$-agonists on capillary-alveolar permeability or edema fluid reabsorption. An aggravation of lung injury after an elevation in pulmonary blood flow has been frequently described in direct injuries of the lung such as OA injury $[15,23,28,32]$. In contrast, indirect lung injuries secondary to endotoxin infusion or severe sepsis seem to be less sensitive to variations in pulmonary blood flow and can be improved by $\beta 2$-agonist therapies [38-40].

A final limitation of our study is the intravenous mode of terbutaline administration which may have provoked more hemodynamic effects than other routes. Aerosolized administration has been proposed to limit the systemic effects of the $\beta 2$-agonists [41]. Atabai and colleagues [42] have shown that physiologically effective alveolar concentrations of salbutamol (10-6 M) may be delivered with conventional systems in patients with pulmonary edema. However, the recent ALTA study [12] failed to find a beneficial effect of aerosolized albuterol therapy in a large randomized, placebo-controlled trial.

\section{Clinical implications}

For everyday practice, our animal model may suggest that therapies inducing an increase in $\mathrm{CO}$ and a decrease in PVR have the potential to heighten the early increase in protein transport from plasma to alveoli within the acutely injured lung. Moreover, the removal of proteins from alveolar space is much slower than alveolar fluid clearance [43]. This accumulation of plasma proteins may contribute to the development of fibroproliferation [1] and lung fibrosis, which contribute to a negative outcome [2]. Our data are consistent with the notion, recently emphasized by experimental [15] and clinical [44] publications, that the vascular side of the capillary-alveolar membrane cannot be ignored.

\section{Conclusions}

Our BAL technique allowed the monitoring of the time course of capillary-alveolar barrier leakage of macromolecules and it's recovery in a pre-clinical model of ARDS. We found that an infusion of terbutaline, started 90 minutes after the onset of
OA injury, increased capillary-alveolar transport of FITC-D70. We speculate that the hemodynamic effects of terbutaline, may have contributed to this increased leakage of macromolecules, and to the recruitment of leaky capillaries thereby increasing the capillary exchange surface area. These findings suggest that therapies inducing an increase in $\mathrm{CO}$ and a decrease in PVR have the potential to heighten the early increase in protein transport from plasma to alveoli within the acutely injured lung.

\section{Key messages}

- Capillary-alveolar permeability to macromolecules (FITC-D70) was measured every 15 minutes for 3 hours, in an OAARDS model in anesthetized dogs.

- The time course of injury showed a peak of permeability 30 minutes after the OA infusion, followed by a slow recovery.

- A treatment by terbutaline intravenous infusion, started 90 minutes after the onset of OA injury, increased capillary-alveolar permeability to FITC-D70.

- Hemodynamic effects of terbutaline, may have recruited leaky capillaries and increased the capillary exchange surface area.

- Therapies inducing an increase in $\mathrm{CO}$ and a decrease in PVR may aggravate the protein leakage from plasma to alveoli within the acutely injured lung.

\section{Competing interests}

All the authors of this paper declare that they have no competing interests.

\section{Authors' contributions}

RB collected the samples and data, performed the data analysis, and wrote the initial draft and the final manuscript. SB and DA participated in data collection and in revising the final manuscript.

JLM directed the mathematical analysis and participated in drafting the initial manuscript. FG conceived the premise and participated in data collection, interpretation and analysis, and in revising the final manuscript. All authors have read and approved the final manuscript. 


\section{Additional files}

The following Additional files are available online:

\section{Additional file 1}

Word file with a proposed explanation of the twocompartment model used to interpret the data and detail the calculation of the capillary-alveolar leakage coefficient $\mathrm{K}_{\mathrm{BA}}$. See http://www.biomedcentral.com/content/ supplementary/cc8137-S1.doc

\section{Acknowledgements}

This study was supported by a grant from the Fondation pour l'Avenir. We thank Ms. Angélique Brouta (Laboratoire TIMC) and Mrs. Catherine Mangournet (Département de Biologie Intégrée) for their technical assistance.

\section{References}

1. Fuchs-Buder T, de Moerloose P, Ricou B, Reber G, Vifian C, Nicod L, Romand JA, Suter PM: Time course of procoagulant activity and $D$ dimer in bronchoalveolar fluid of patients at risk for or with acute respiratory distress syndrome. Am J Respir Crit Care Med 1996, 153:163-167.

2. Ware LB, Matthay MA: The acute respiratory distress syndrome. N Engl J Med 2000, 342:1334-1349.

3. Idell S: Coagulation, fibrinolysis, and fibrin deposition in acute lung injury. Crit Care Med 2003, 31:S213-220.

4. Clark JG, Milberg JA, Steinberg KP, Hudson LD: Type III procollagen peptide in the adult respiratory distress syndrome. Association of increased peptide levels in bronchoalveolar lavage fluid with increased risk for death. Ann Intern Med 1995, 122:17-23.

5. Meduri GU, Kohler G, Headley S, Tolley E Stentz F, Postlethwaite A: Inflammatory cytokines in the BAL of patients with ARDS. Persistent elevation over time predicts poor outcome. Chest 1995, 108:1303-1314.

6. Briot R, Bayat S, Anglade D, Martiel JL, Grimbert F: Monitoring the capillary-alveolar leakage in an A.R.D.S. model using broncho-alveolar lavage. Microcirculation 2008, 15:237-249.

7. Maris NA, de Vos AF, Dessing MC, Spek CA, Lutter R, Jansen HM, Zee JS van der, Bresser $P$, Poll T van der: Antiinflammatory effects of salmeterol after inhalation of lipopolysaccharide by healthy volunteers. Am J Respir Crit Care Med 2005, 172:878-884.

8. Perkins GD, McAuley DF, Richter A, Thickett DR, Gao F: Benchto-bedside review: beta2-agonists and the acute respiratory distress syndrome. Crit Care 2004, 8:25-32.

9. McAuley DF, Frank JA, Fang X, Matthay MA: Clinically relevant concentrations of beta2-adrenergic agonists stimulate maximal cyclic adenosine monophosphate-dependent airspace fluid clearance and decrease pulmonary edema in experimental acid-induced lung injury. Crit Care Med 2004, 32:1470-1476

10. Matthay MA, Folkesson HG, Clerici C: Lung epithelial fluid transport and the resolution of pulmonary edema. Physiol Rev 2002, 82:569-600.

11. Perkins GD, McAuley DF, Thickett DR, Gao F: The beta-Agonist Lung Injury Trial (BALTI): A Randomized Placebo-controlled Clinical Trial. Am J Respir Crit Care Med 2006, 173:281-287.

12. Matthay M, Brower R, Thompson B, Schoenfeld D, Eisner M, Carson S, Moss M, Douglas I, Hite D, Maclntyre N, Liu KD: Randomized, Placebo-Controlled Trial of an Aerosolized Beta-2 Adrenergic Agonist (Albuterol) for the Treatment of Acute Lung Injury. Am J Respir Crit Care Med 2009, 179:A2166.
13. Groeneveld AB, den Hollander W, Straub J, Nauta JJ, Thijs LG: Effects of $\mathrm{N}$-acetylcysteine and terbutaline treatment on hemodynamics and regional albumin extravasation in porcine septic shock. Circ Shock 1990, 30:185-205.

14. Wetterberg T, Svensjo E, Larsson A, Sigurdsson G, Z GW, Willen $\mathrm{H}$ : Acute lung injury monitored with radiolabeled transferrin and lung volume measurements. Acta Anaesthesiol Scand 1989, 33:359-368.

15. Schreiber T, Hueter L, Gaser E, Schmidt B, Schwarzkopf K, Karzai W: Effects of a catecholamine-induced increase in cardiac output on lung injury after experimental unilateral pulmonary acid instillation. Crit Care Med 2007, 35:1741-1748.

16. Hakim TS, Maarek JM, Chang HK: Estimation of pulmonary capillary pressure in intact dog lungs using the arterial occlusion technique. Am Rev Respir Dis 1989, 140:217-224.

17. Bayat S, Anglade D, Menaouar A, Martiel JL, Lafond JL, Benchetrit G, Grimbert FA: In vivo measurement of lung capillary-alveolar macromolecule permeability by saturation bronchoalveolar lavage. Crit Care Med 2000, 28:2937-2942.

18. Berthiaume $Y$, Matthay MA: Alveolar edema fluid clearance and acute lung injury. Respir Physio/ Neurobio/ 2007, 159:350-359.

19. Reed RK, Townsley MI, Korthuis RJ, Taylor AE: Analysis of lymphatic protein flux data. V. Unique PS products and sigma dS at low lymph flows. Am J Physiol 1991, 261: H728-740.

20. Ishibashi M, Reed RK, Townsley MI, Parker JC, Taylor AE: Albumin transport across pulmonary capillary-interstitial barrier in anesthetized dogs. J App/ Physio/ 1991, 70:2104-2110.

21. Grimbert FA, Parker JC, Taylor AE: Increased pulmonary vascular permeability following acid aspiration. J Appl Physiol 1981, 51:335-345.

22. Grimbert FA, Martin D, Parker JC, Taylor AE: Lymph flow during increases in pulmonary blood flow and microvascular pressure in dogs. Am J Physiol 1988, 255:H1149-1155.

23. Hasinoff I, Ducas J, Prewitt RM: Increased cardiac output increases lung water in canine permeability pulmonary edema. J Crit Care 1988, 3:225-231.

24. Schuster DP: ARDS: clinical lessons from the oleic acid model of acute lung injury. Am J Respir Crit Care Med 1994, 149:245-260.

25. Leeman M, Lejeune $P$, Closset J, Vachiery JL, Melot C, Naeije R: Nature of pulmonary hypertension in canine oleic acid pulmonary edema. J Appl Physiol 1990, 69:293-298.

26. Brimioulle S, Julien V, Gust R, Kozlowski JK, Naeije R, Schuster DP: Importance of hypoxic vasoconstriction in maintaining oxygenation during acute lung injury. Crit Care Med 2002, 30:874-880.

27. Bishop MJ, Cheney FW: Vasodilators worsen gas exchange in dog oleic-acid lung injury. Anesthesiology 1986, 64:435-439.

28. Pellett AA, Lord KC, Champagne MS, deBoisblanc BP, Johnson RW, Levitzky MG: Pulmonary capillary pressure during acute lung injury in dogs. Crit Care Med 2002, 30:403-409.

29. Dauber IM, Weil JV: Lung injury edema in dogs. Influence of sympathetic ablation. J Clin Invest 1983, 72:1977-1986.

30. Schuster DP, Stephenson AH, Holmberg S, Sandiford P: Effect of eicosanoid inhibition on the development of pulmonary edema after acute lung injury. J Appl Physiol 1996, 80:915-923

31. Velazquez M, Schuster DP: Pulmonary blood flow distribution after lobar oleic acid injury: a PET study. J Appl Physiol 1988 65:2228-2235.

32. Anglade D, Corboz M, Menaouar A, Parker JC, Sanou S, Bayat S, Benchetrit G, Grimbert FA: Blood flow vs. venous pressure effects on filtration coefficient in oleic acid-injured lung. $J$ Appl Physiol 1998, 84:1011-1023.

33. Schuster DP, Haller JW, Velazquez M: A positron emission tomographic comparison of diffuse and lobar oleic acid lung injury. J Appl Physiol 1988, 64:2357-2365.

34. Lachmann B, Robertson B, Vogel J: In vivo lung lavage as an experimental model of the respiratory distress syndrome. Acta Anaesthesiol Scand 1980, 24:231-236.

35. Cohen $A B$, Batra GK: Bronchoscopy and lung lavage induced bilateral pulmonary neutrophil influx and blood leukocytosis in dogs and monkeys. Am Rev Respir Dis 1980, 122:239-247.

36. Von Essen SG, Robbins RA, Spurzem JR, Thompson AB, McGranaghan SS, Rennard SI: Bronchoscopy with bronchoalveolar lavage causes neutrophil recruitment to the lower respiratory tract. Am Rev Respir Dis 1991, 144:848-854. 
37. Martin TR, Pistorese BP, Chi EY, Goodman RB, Matthay MA: Effects of leukotriene B4 in the human lung. Recruitment of neutrophils into the alveolar spaces without a change in protein permeability. J Clin Invest 1989, 84:1609-1619.

38. Youssef HA, Sigurdsson GH, Christenson JT, Owunwanne A: Use of indium-111-labeled transferrin to study plasma extravasation during endotoxin shock and the effects of the beta-2 agonist terbutaline. Am J Physiol Imaging 1991, 6:85-89.

39. Knox J, Youn YK, Lalonde C, Demling R: Effect of dobutamine on oxygen consumption and fluid and protein losses after endotoxemia. Crit Care Med 1991, 19:525-531.

40. Gnidec AG, Finley RR, Sibbald WJ: Effect of dobutamine on lung microvascular fluid flux in sheep with "sepsis syndrome". Chest 1988, 93:180-186.

41. Licker M, Tschopp JM, Robert J, Frey JG, Diaper J, Ellenberger C: Aerosolized salbutamol accelerates the resolution of pulmonary edema after lung resection. Chest 2008, 133:845-852.

42. Atabai K, Ware LB, Snider ME, Koch P, Daniel B, Nuckton TJ, Matthay MA: Aerosolized beta(2)-adrenergic agonists achieve therapeutic levels in the pulmonary edema fluid of ventilated patients with acute respiratory failure. Intensive Care Med 2002, 28:705-711.

43. Hastings RH, Folkesson HG, Matthay MA: Mechanisms of alveolar protein clearance in the intact lung. Am J Physiol Lung Cell Mol Physiol 2004, 286:L679-689.

44. Wiedemann HP, Wheeler AP, Bernard GR, Thompson BT, Hayden D, deBoisblanc B, Connors AF, Hite RD, Harabin AL: Comparison of two fluid-management strategies in acute lung injury. $N$ Engl J Med 2006, 354:2564-2575. 